\title{
A Chlorinating Reagent Yields Vinyl Chlorides with High Regioselectivity under Heterogeneous Gold Catalysis
}

\author{
Shengzong Liang, ${ }^{\dagger, \S}$ Rene Ebule, ${ }^{\dagger, \S}$ Gerald B. Hammond, ${ }^{* \dagger} \dagger$ and Bo $\mathrm{Xu}^{*, \ddagger}$ \\ ${ }^{\dagger}$ Department of Chemistry, University of Louisville, Louisville, Kentucky 40292, United States \\ ${ }^{\ddagger}$ College of Chemistry, Chemical Engineering and Biotechnology, Donghua University, Shanghai 201620, China
}

\section{Supporting Information}

ABSTRACT: A novel chlorinating reagent with a high concentration of $\mathrm{HCl}$ has enabled the highly regioselective hydrochlorination of unactivated alkynes using a commercial nanogold catalyst. No overchlorination or hydration products were formed, and various functional groups were tolerated. This hydrochlorination method could be conducted under open air.

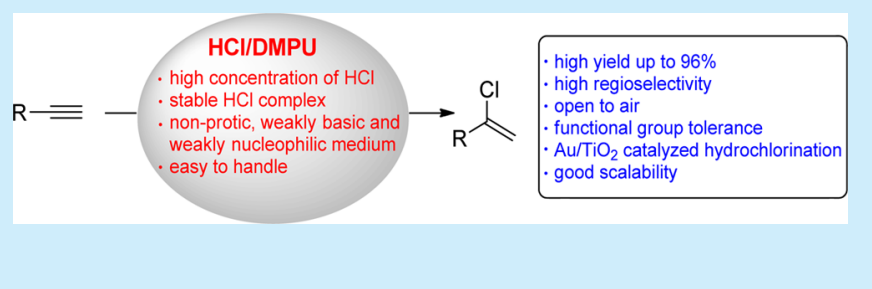

$\mathrm{C}$ hlorine-containing compounds are prevalent in natural products, pharmaceuticals, and agrochemicals. ${ }^{1}$ They also play a significant role in organic synthesis because of their broad applications as useful intermediates for transition-metalcatalyzed carbon-carbon and carbon-heteroatom coupling reactions such as Buchwald-Hartwig amination ${ }^{2}$ and SuzukiMiyaura coupling. ${ }^{3}$ Among various chlorinated compounds, vinyl chlorides stand out as an important group. Compared to traditional synthesis of vinyl chlorides from carbonyl compounds, ${ }^{4}$ the direct hydrochlorination of alkynes from $\mathrm{HCl}$ is a more straightforward and higher atom-efficiency method. Indeed, several hydrochlorinations of alkynes have been developed using $\mathrm{LiCl}, \mathrm{MgCl}_{2}, \mathrm{AcCl}$, and $\mathrm{TMSCl}$ as a chloride source. ${ }^{5}$ However, the direct hydrochlorination of unactivated alkynes using $\mathrm{HCl}$ as a chlorine source has been rarely reported. Dai's group found that $\mathrm{HCl}$ gas could hydrochlorinate electron-rich phenylacetylenes, although hydrated products were also formed. ${ }^{6}$ One remarkable hydrochlorination of alkyne was reported by Derien's group. They developed a highly efficient ruthenium-catalyzed hydrochlorination of alkynes. Both good yield and selectivity were achieved, although strict oxygen- and water-free operation was needed in this strategy. ${ }^{7}$ More recently, Corma and coworkers reported a hydrochlorination of alkynes using hydrogen chloride in dioxane and catalytic amounts of gold nanoparticles, but functional group tolerance was not deeply explored. $^{8}$

Searching for an appropriate $\mathrm{HCl}$-based chlorinating reagent is crucial for a direct hydrochlorination reaction. The commercial sources of $\mathrm{HCl}$ are usually not very effective chlorinating reagents due to the low activity caused by the relatively low concentration of $\mathrm{HCl}$ (Scheme 1). Moreover, the nucleophilicity of chloride in protic mediums such as water and alcohol is greatly reduced. ${ }^{9}$ Our group has previously developed a novel nucleophilic fluorinating reagent HF/DMPU based on the concept of hydrogen bond basicity $\left(\mathrm{p} K_{\mathrm{BHX}}\right) .{ }^{10}$ Considering that DMPU (1,3-dimethyl-3,4,5,6-tetrahydro-2-pyrimidinone)
Scheme 1. Comparison of Different Formulations of $\mathrm{HCl}$ Solutions

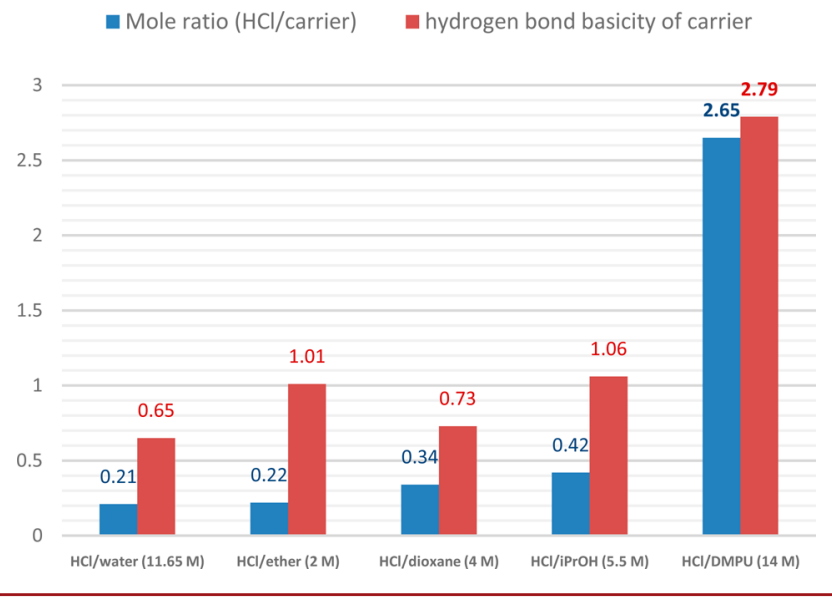

is weakly basic and weakly nucleophilic and is a strong hydrogen-bond acceptor, we assumed that it would be also an ideal chlorinating reagent carrier for organic reactions. To our delight, the synthesized $\mathrm{HCl} / \mathrm{DMPU}$ presents an extraordinarily high mole ratio (2.65) between $\mathrm{HCl}$ and DMPU. In contrast, other commercially available $\mathrm{HCl}$ solutions have a much lower mole ratio, such as 0.21 for $\mathrm{HCl} /$ water, 0.22 for $\mathrm{HCl}$ /ether, 0.34 for $\mathrm{HCl} /$ dioxane, and 0.42 for $\mathrm{HCl} /{ }_{i} \mathrm{PrOH}$. The molarity of $\mathrm{HCl} / \mathrm{DMPU}(43 \% \mathrm{w} / \mathrm{w})$ is $14 \mathrm{M}$, which is also higher than other commercially available $\mathrm{HCl}$ solutions, indicating that $\mathrm{HCl} / \mathrm{DMPU}$ might exhibit higher activity for nucleophilic chlorination reactions. In addition, as compared with the $\mathrm{p} K_{\mathrm{BHX}}$ of other $\mathrm{HCl}$ solutions such as 0.65 for $\mathrm{HCl}$ / water, 1.01 for $\mathrm{HCl}$ /ether, 0.73 for $\mathrm{HCl} /$ dioxane, and 1.06 for $\mathrm{HCl} / \mathrm{iPrOH}$, the larger hydrogen-bond basicity $\left(\mathrm{p} K_{\mathrm{BHX}}\right)$ of DMPU (2.79) would also increase the nucleophilicity of

Received: July 10, 2017

Published: August 15, 2017 
Table 1. Screening of Hydrochlorination of 1-Octyne ${ }^{a}$

\begin{tabular}{|c|c|c|c|c|c|c|}
\hline entry & $\mathrm{HCl}$ (equiv) & solvent & temp $\left({ }^{\circ} \mathrm{C}\right)$ & time $(\mathrm{h})$ & $2 / 2^{\prime}$ & yield (\%) \\
\hline 1 & $\mathrm{HCl} / \mathrm{Et}_{2} \mathrm{O}(2)$ & DCE & 80 & 5 & $100 / 0$ & 8 \\
\hline 2 & $\mathrm{HCl} / i \operatorname{PrOH}(2)$ & DCE & 80 & 5 & $100 / 0$ & 15 \\
\hline 3 & $\mathrm{HCl} / \mathrm{H}_{2} \mathrm{O}(2)$ & DCE & 80 & 5 & $100 / 0$ & 4 \\
\hline 4 & $\mathrm{HCl} / \mathrm{DMPU}(2)$ & DCE & 80 & 5 & $90 / 10$ & 90 \\
\hline 5 & $\mathrm{HCl} / \mathrm{DMPU}(2)$ & tol & 80 & 5 & $88 / 12$ & 67 \\
\hline 6 & $\mathrm{HCl} / \mathrm{DMPU}(2)$ & dioxane & 80 & 5 & $87 / 13$ & 93 \\
\hline 7 & HCl/DMPU (2) & $\mathrm{MeCN}$ & 80 & 5 & $92 / 8$ & 80 \\
\hline 8 & $\mathrm{HCl} / \mathrm{DMPU}(2)$ & $t-\mathrm{BuOH}$ & 80 & 5 & $99 / 1$ & 23 \\
\hline 9 & $\mathrm{HCl} / \mathrm{DMPU}(2)$ & DMF & 80 & 5 & $98 / 2$ & 55 \\
\hline 10 & HCl/DMPU (4) & DMF & 80 & 14 & $98 / 2$ & 66 \\
\hline $11^{b}$ & $\mathrm{HCl} / \mathrm{DMPU}$ (4) & DMF & 80 & 14 & $98 / 2$ & 83 \\
\hline 12 & $\mathrm{HCl} / \mathrm{DMPU}(4)$ & DMF & 100 & 14 & $98 / 2$ & 85 \\
\hline 13 & $\mathrm{HCl} / \mathrm{DMPU}(4)$ & DMA & 100 & 14 & $98 / 2$ & 77 \\
\hline 14 & HCl/DMPU (4) & NMP & 100 & 14 & $99 / 1$ & 45 \\
\hline $15^{c}$ & $\mathrm{HCl} / \mathrm{DMPU}(4)$ & DMF & 100 & 14 & $98 / 2$ & 68 \\
\hline $16^{d}$ & $\mathrm{HCl} / \mathrm{DMPU}$ (4) & DMF & 100 & 14 & $98 / 2$ & 57 \\
\hline $17^{e}$ & $\mathrm{HCl} / \mathrm{DMPU}(4)$ & DMF & 100 & 7 & $98 / 2$ & 91 \\
\hline $18^{f}$ & $\mathrm{HCl} / \mathrm{DMPU}(4)$ & DMF & 100 & 14 & $98 / 2$ & 71 \\
\hline $19^{g}$ & $\mathrm{HCl} / \mathrm{DMPU}(4)$ & DMF & 100 & 14 & $100 / 0$ & 9 \\
\hline $20^{h}$ & $\mathrm{HCl} / \mathrm{DMPU}$ (4) & DMF & 100 & 14 & $100 / 0$ & 10 \\
\hline $21^{i}$ & HCl/DMPU (4) & DMF & 100 & 14 & $99 / 1$ & 46 \\
\hline
\end{tabular}

${ }^{a}$ Both regioselectivity and yield were determined by ${ }^{1} \mathrm{H} \mathrm{NMR} .{ }^{b} \mathrm{Au} / \mathrm{TiO}_{2}(4 \mathrm{~mol} \%)$ was used. ${ }^{c}[1 \mathrm{a}]=0.5 \mathrm{M} .{ }^{d}[1 \mathrm{a}]=0.2 \mathrm{M} .{ }^{e}[1 \mathrm{a}]=2 \mathrm{M} .{ }^{f} \mathrm{Au} /$ $\mathrm{Al}_{2} \mathrm{O}_{3}(2 \mathrm{~mol} \%)$ was used. ${ }^{g} \mathrm{No} \mathrm{Au} / \mathrm{TiO}_{2}$ was used. ${ }^{h} \mathrm{TiO}_{2}$ (1 equiv) was used. ${ }^{i} \mathrm{PPh}_{3} \mathrm{AuCl}(2 \mathrm{~mol} \%)$ and $\mathrm{AgOTf}(2 \mathrm{~mol} \%)$ were used.

chloride and, meanwhile, form a stable and highly concentrated complex with $\mathrm{HCl}$. Moreover, even at a high mole ratio, we found that the $\mathrm{HCl} / \mathrm{DMPU}$ complex exhibited less fuming than the common concentrated $\mathrm{HCl}$ water solution $(\mathrm{HCl} /$ water $=$ $0.21)$.

Gold catalysis is well-known for its excellent ability to activate $\mathrm{C}-\mathrm{C}$ unsaturated bonds, thus allowing the generation of a heteroatom-carbon bond via the nucleophilic addition onto the gold-bound $\pi$-bond intermediate. ${ }^{11}$ Commercially available gold catalysts such as $\mathrm{PPh}_{3} \mathrm{AuCl}$ are usually stabilized through formation of $\mathrm{Au}-\mathrm{Cl}$ complexes due to the relatively strong bond energy between gold and chlorine. ${ }^{12}$ Thus, silver salts are usually needed to break the strong $\mathrm{Au}-\mathrm{Cl}$ bond to release active cationic gold species. In our previous work, gold nanoparticles have been successfully used as catalysts for various organic transformations. ${ }^{13}$ In particular, we found that the weaker cationic character of gold nanoparticles allowed them to tolerate a strong basic environment, leading, for example, to the hydration of alkynes under basic conditions without affecting acid-sensitive functionalities. ${ }^{13 \mathrm{~d}}$ Therefore, we hypothesized that this property may also enable the chloride compatibility of gold nanoparticles. Herein, we are glad to report the first commercially available gold nanoparticlecatalyzed hydrochlorination of unactivated alkynes with $\mathrm{HCl}$ / DMPU.

To test the feasibility of our hypothesis, we chose the hydrochlorination of 1-octyne as a model reaction with $\mathrm{Au} /$ $\mathrm{TiO}_{2}(2 \mathrm{~mol} \%)$ as the catalyst. Not surprisingly, three commercially available $\mathrm{HCl}$ solutions were ineffective for this transformation because of the low concentration of $\mathrm{HCl}$ (Table 1 , entries $1-3$ ). However, when $\mathrm{HCl} / \mathrm{DMPU}$ was used, a very high yield of hydrochlorinated product (90\%) was observed, and good regioselectivity was also achieved (Table 1, entry 4).
To further increase the regioselectivity, we screened different solvents. Nonpolar or less polar solvents such as toluene, dioxane, and acetonitrile did not improve the selectivity (Table 1 , entries $5-7) \cdot t-\mathrm{BuOH}$ provided the desired product with better selectivity yet much poorer yield (Table 1 , entry 8 ). DMF was ultimately considered as the best solvent because of its moderate yield and higher regioselectivity (Table 1, entry 9). More $\mathrm{HCl} / \mathrm{DMPU}$ (4 equiv) could increase the yield to $66 \%$ (Table 1, entry 10). And with more $\mathrm{Au} / \mathrm{TiO}_{2}$ (4 mol \%), the yield could be further enhanced to $83 \%$ (Table 1, entry 11 ). We found that a higher reaction temperature works equally well (Table 1, entry 12). We also tested other amide types of solvent such as DMA and NMP, but they were inefficient (Table 1, entries 13 and 14). Different reaction concentrations were also screened (Table 1, entries 15-17), and a higher concentration (2 M) gave a $91 \%$ yield. $\mathrm{Au} / \mathrm{Al}_{2} \mathrm{O}_{3}$ was also used in this hydrochlorination reaction, but its efficiency was not as good as $\mathrm{Au} / \mathrm{TiO}_{2}$ (Table 1 , entry 18 ). $\mathrm{Au} / \mathrm{TiO}_{2}$ was essential for achieving high efficiency for this transformation because when no $\mathrm{Au} / \mathrm{TiO}_{2}$ was used or just the support $\mathrm{TiO}_{2}$ was used, only $9 \%$ and $10 \%$ of products were observed, respectively (Table 1 , entries 19 and 20). We found that a homogeneous gold catalyst, using our optimal conditions, was much less effective than heterogeneous gold nanoparticles (Table 1, entry 21).

With optimized conditions in hand, we evaluated the substrate scope. The vinyl chlorides derived from aliphatic terminal alkynes were obtained in good yields and regioselectivities (Scheme 2, 2a-2c). Our hydrochlorination method also exhibited excellent functional group tolerance. Both cyano and carboxylic acid groups could be tolerated (Scheme 2, 2d and 2e). A chloro-containing alkyne also provided a corresponding Markovnikov vinyl chloride product in good yield (Scheme 2, 2f). Both benzyl ether and allyl ether 
Scheme 2. Au/ $\mathrm{TiO}_{2}$ Catalyzed Hydrochlorination of Alkynes with $\mathrm{HCl} / \mathrm{DMPU}^{a, b}$

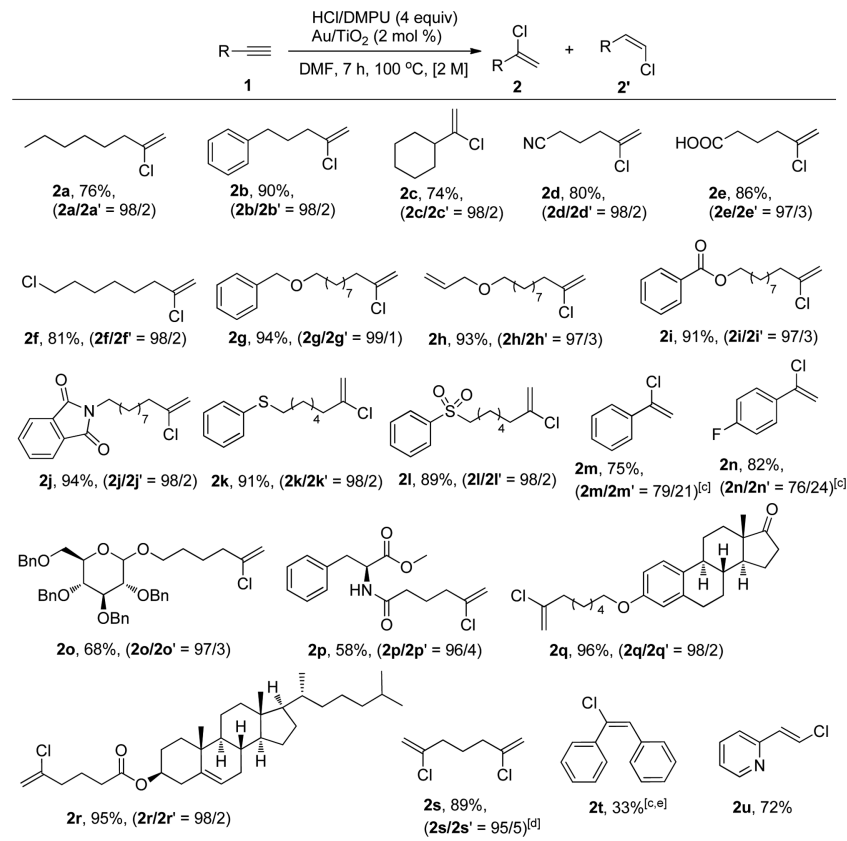

${ }^{a}$ Experiments were performed with 1 (0.4 mmol), HCl/DMPU (43\% w/w, $1.6 \mathrm{mmol}), \mathrm{Au} / \mathrm{TiO}_{2}(2 \mathrm{~mol} \%)$ in $\operatorname{DMF}(0.2 \mathrm{~mL})$ at $100{ }^{\circ} \mathrm{C}$. ${ }^{b}$ Isolated yields. ${ }^{c}$ Not isolated; yields were determined by ${ }^{1} \mathrm{H}$ NMR using 1,3,5-trimethoxybenzene as internal standard. Regioselectivity was dertemined by GCMS. ${ }^{d} \mathrm{HCl} / \mathrm{DMPU}(3.2 \mathrm{mmol})$ was used. ${ }^{e} \mathrm{Au} /$ $\mathrm{TiO}_{2}(4 \mathrm{~mol} \%)$ was used at $120^{\circ} \mathrm{C}$ for $16 \mathrm{~h}$.

substrates worked very well under standard condition (Scheme $2, \mathbf{2 g}$ and $\mathbf{2 h}$ ). Both ester and imide groups remained intact during the hydrochlorination process (Scheme 2, $\mathbf{2} \mathbf{i}$ and $\mathbf{2 j}$ ). Sulfane- and sulfone-containing substrates also gave good yields and selectivity without any problem (Scheme 2, 2k and 2l). Aromatic terminal alkynes were also examined; however, more anti-Markovnikov products were formed (Scheme 2, $\mathbf{2 m}$ and 2n). To test the potential of this strategy in the late-stage hydrochlorination of complex molecules, the terminal alkynes attached to biomolecular scaffolds were then examined. A structurally complex glycoside could give corresponding vinyl chloride 20 without loss of the glycosyl linkage (Scheme 2, 2o). Protected amino acids such as a phenylalanine derivative were also able to undergo hydrochlorination with a moderate yield (Scheme 2, 2p). An estrone derivative bearing an alkyne moiety was also a suitable substrate for such a transformation (Scheme 2, 2q). Lastly, a cholesterol ester derivative could smoothly provide the desired vinyl chloride $2 \mathbf{r}$ with excellent yield and selectivity as well (Scheme 2, 2r). In addition, we also tried 1,6heptadiyne, which led to the formation of a divinyl chloride product (Scheme 2, 2s). Finally, an internal alkyne diphenylacetylene was also examined, which provided the cis-vinyl chloride in 33\% yield (Scheme 2, 2t).

It should be noted that when 2-ethynylpyridine was tested, an anti-Markovnikov product was generated, and the cisselectivity of this product is consistent with the cis-addition commonly observed in nanogold catalyzed $\mathrm{Si}-\mathrm{Si}$ or $\mathrm{Si}-\mathrm{H}$ addition to alkynes or semireduction of alkynes, which suggested that this hydrochlorination of alkynes was, indeed, catalyzed by gold nanoparticles instead of leaching gold species (Scheme 2, 2u).
Finally, to demonstrate the applicability of our strategy to gram-scale synthesis, we conducted the hydrochlorination of 10 mmol of 1a under standard condtions; after $7 \mathrm{~h}$, the same yield as that for the reaction in small scale was observed, and the regioselectivity was also not influenced (eq 1).

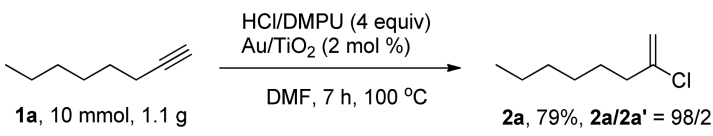

In summary, we have found a highly efficient chlorinating reagent in a nonprotic, weakly basic, and weakly nucleophilic medium, DMPU. It has a higher concentration of $\mathrm{HCl}$ than commercial $\mathrm{HCl}$ sources. These features may be useful in other organic transformations involving $\mathrm{HCl}$. $\mathrm{HCl} / \mathrm{DMPU}$ was an effective reagent for the synthesis of vinyl chlorides from alkynes using heterogeneous nanogold catalysis. Good yields and regioselectivity were observed, and a variety of functionalities were compatible with this hydrochlorination process. Moreover, this method was easily scaled up and did not require strict oxygen- and water-free conditions.

\section{ASSOCIATED CONTENT}

\section{Supporting Information}

The Supporting Information is available free of charge on the ACS Publications website at DOI: 10.1021/acs.orglett.7b02101.

Experimental detail and copies of NMR spectra (PDF)

\section{AUTHOR INFORMATION}

\section{Corresponding Authors}

*E-mail: bo.xu@dhu.edu.cn.

*E-mail: gb.hammond@Louisville.edu.

ORCID

Gerald B. Hammond: 0000-0002-9814-5536

\section{Author Contributions}

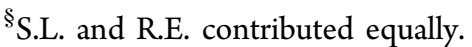

Notes

The authors declare no competing financial interest.

\section{ACKNOWLEDGMENTS}

We are grateful to the National Institutes of Health for financial support (1R01GM121660-01) and to the National Science Foundation (CHE-1401700) for supporting the preliminary phase of this research. B.X. is grateful to the National Science Foundation of China for financial support (NSFC-21472018).

\section{REFERENCES}

(1) (a) Engvild, K. C. Phytochemistry 1986, 25, 781-791. (b) Gribble, G. W. Acc. Chem. Res. 1998, 31, 141-152. (c) Hernandes, M.; Cavalcanti, S. M.; Moreira, D. R.; de Azevedo, W., Jr.; Leite, A. C. Curr. Drug Targets 2010, 11, 303-314. (d) Jeschke, P. Pest Manage. Sci. 2010, 66, 10-27.

(2) (a) Hartwig, J. F. Acc. Chem. Res. 2008, 41, 1534-1544. (b) RuizCastillo, P.; Buchwald, S. L. Chem. Rev. 2016, 116, 12564-12649.

(3) (a) Martin, R.; Buchwald, S. L. Acc. Chem. Res. 2008, 41, 14611473. (b) Miyaura, N.; Suzuki, A. Chem. Rev. 1995, 95, 2457-2483. (c) Han, F.-S. Chem. Soc. Rev. 2013, 42, 5270-5298.

(4) (a) Su, W.; Jin, C. Org. Lett. 2007, 9, 993-996. (b) Kamei, K.; Maeda, N.; Tatsuoka, T. Tetrahedron Lett. 2005, 46, 229-232. 
(c) Spaggiari, A.; Vaccari, D.; Davoli, P.; Torre, G.; Prati, F. J. Org. Chem. 2007, 72, 2216-2219.

(5) (a) Ma, S.; Lu, X.; Li, Z. J. Org. Chem. 1992, 57, 709-713. (b) Sun, A.; Huang, X. Synthesis 2000, 2000, 1819-1821. (c) Yu, W.; Jin, Z. J. Am. Chem. Soc. 2000, 122, 9840-9841. (d) Mulder, J. A.; Kurtz, K. C. M.; Hsung, R. P.; Coverdale, H.; Frederick, M. O.; Shen, L.; Zificsak, C. A. Org. Lett. 2003, 5, 1547-1550. (e) Zhu, G.; Chen, D.; Wang, Y.; Zheng, R. Chem. Commun. 2012, 48, 5796-5798. (f) Derosa, J.; Cantu, A. L.; Boulous, M. N.; O’Duill, M. L.; Turnbull, J. L.; Liu, Z.; De La Torre, D. M.; Engle, K. M. J. Am. Chem. Soc. 2017, 139, 5183-5193.

(6) Xu, C.-X.; Ma, C.-H.; Xiao, F.-R.; Chen, H.-W.; Dai, B. Chin. Chem. Lett. 2016, 27, 1683-1685.

(7) Dérien, S.; Klein, H.; Bruneau, C. Angew. Chem., Int. Ed. 2015, 54, $12112-12115$.

(8) During the preparation of this manuscript, Corma and coworkers reported a hydrochlorination of alkynes with hydrogen chloride using catalytic gold nanoparticles: Oliver-Meseguer, J.; Doménech-Carbó, A.; Boronat, M.; Leyva-Pérez, A.; Corma, A. Angew. Chem., Int. Ed. 2017, 56, 6435-6439.

(9) (a) Laurence, C.; Berthelot, M. Perspect. Drug Discovery Des. 2000, 18, 39-60. (b) Minegishi, S.; Loos, R.; Kobayashi, S.; Mayr, H. J. Am. Chem. Soc. 2005, 127, 2641-2649.

(10) (a) Laurence, C.; Brameld, K. A.; Graton, J. r. m.; Le Questel, J.Y.; Renault, E. J. Med. Chem. 2009, 52, 4073-4086. (b) Okoromoba, O. E.; Han, J.; Hammond, G. B.; Xu, B. J. Am. Chem. Soc. 2014, 136, 14381-14384. (c) Okoromoba, O. E.; Li, Z.; Robertson, N.; Mashuta, M. S.; Couto, U. R.; Tormena, C. F.; Xu, B.; Hammond, G. B. Chem. Commun. 2016, 52, 13353-13356. (d) Okoromoba, O. E.; Hammond, G. B.; Xu, B. Org. Lett. 2015, 17, 3975-3977.

(11) (a) Dorel, R.; Echavarren, A. M. Chem. Rev. 2015, 115, 90289072. (b) Hashmi, A. S. K. Chem. Rev. 2007, 107, 3180-3211. (c) Li, Z.; Brouwer, C.; He, C. Chem. Rev. 2008, 108, 3239-3265. (d) Bandini, M. Chem. Soc. Rev. 2011, 40, 1358-1367. (e) Corma, A.; Leyva-Pérez, A.; Sabater, M. J. Chem. Rev. 2011, 111, 1657-1712. (f) Liu, L.-P.; Hammond, G. B. Chem. Soc. Rev. 2012, 41, 3129-3139. (12) (a) Evans, C. J.; Lesarri, A.; Gerry, M. C. L. J. Am. Chem. Soc. 2000, 122, 6100-6105. (b) Brown, J. R.; Schwerdtfeger, P.; Schröder, D.; Schwarz, H. J. Am. Soc. Mass Spectrom. 2002, 13, 485-492.

(13) (a) Liang, S.; Hammond, G. B.; Xu, B. Chem. Commun. 2016, 52, 6013-6016. (b) Liang, S.; Monsen, P.; Hammond, G. B.; Xu, B. Org. Chem. Front. 2016, 3, 505-509. (c) Liang, S.; Hammond, L.; Xu, B.; Hammond, G. B. Adv. Synth. Catal. 2016, 358, 3313-3318. (d) Liang, S.; Jasinski, J.; Hammond, G. B.; Xu, B. Org. Lett. 2015, 17, $162-165$. 